\title{
Public Perspectives on Health Human Resources in Primary Healthcare: Context, Choices and Change
}

\section{Point de vue du public sur les ressources humaines en santé dans les soins de santé primaires : contexte, choix et changement}

\author{
S \\ by SANDRA REGAN, RN, MSN, MA, PHD CANDIDATE \\ Assistant Professor \\ Arthur Labatt Family School of Nursing \\ University of Western Ontario \\ London, Ontario
}

SABRINA T. WONG, RN, PHD

Associate Professor and Faculty

School of Nursing and Centre for Health Services and Policy Research

University of British Columbia

Vancouver, BC

DiANE E. WATSON, MBA, PHD

Chief Executive, Bureau of Health Information

Sydney, Australia 


\title{
Public Perspectives on Health Human Resources in Primary Healthcare: Context, Choices and Change
}

\begin{abstract}
The purpose of this study was to examine factors identified by patients as relevant to health human resources (HHR) planning for primary healthcare (PHC). Eleven focus groups were conducted in British Columbia and a thematic analysis was undertaken, informed by a needs-based HHR planning framework. Three themes emerged: (a) the importance of geographic context, (b) change management at the practice level and (c) the need for choices and changes in delivery of PHC. Findings suggest that more attention could be focused on overcoming geographic barriers to providing services, change management within office-based practices, and providing support structures that allow primary care providers to work closer to their full scope of practice. That these factors align with many strategic directions set out by government and planners signals the readiness for change in how PHC is delivered and HHR planned.
\end{abstract}

\section{Résumé}

L'objectif de cette étude est d'examiner les facteurs que les patients estiment pertinents dans la planification des ressources humaines en santé (RHS) pour les soins de santé primaires (SSP). Nous avons constitué 11 groupes de discussion en Colombie-Britannique et nous avons mené une analyse thématique en utilisant un cadre de planification des RHS fondé sur les besoins. Trois thèmes se sont dégagés : (a) l'importance du contexte géographique, (b) la gestion du changement au niveau de la pratique et (c) la nécessité de permettre des choix et des changements dans la prestation des SSP. Les résultats font voir qu'une attention accrue doit être portée à la question des obstacles géographiques dans la prestation des services, à la gestion du changement dans les pratiques et aux structures de soutien qui permettent aux fournisseurs de SSP de travailler plus près de leur champ complet d'activité. Le fait que ces facteurs coïncident avec plusieurs stratégies conçues par le gouvernement et par les planificateurs montre qu'il est temps d'apporter des changements dans la prestation des SSP et dans la planification des RHS.

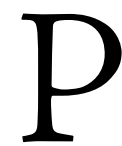
RIMARY HEALTHCARE (PHC) REFORM AND HEALTH HUMAN RESOURCES (HHR) planning are recurring themes in policy discussions and have been identified as areas of high priority for health system renewal and research in many countries (Australian Health Workforce Advisory Committee 2004; Law et al. 2008; Health Council of Canada 2007; National Workforce Taskforce and HR Directorate Department of Health 2002). In Canada, a vision for improvements in these areas, as well as in enhanced accountability and transparency, was central to federal, provincial and territorial investments in a 10 -year plan to strengthen healthcare to 
ensure "that Canadians have access to the care they need, when they need it" (Health Canada 2004). For some time, Canadians have been asking for better access to PHC services, better quality of that care, and more health promotion and disease prevention services (Watson and Kruger 2005; Pollara 2007).

In the past, HHR planning has been carried out intermittently and focused on single healthcare professions in isolation from the broader contextual factors beyond public and media perceptions of surplus or shortage (O'Brien-Pallas 2002). There was also heavy reliance on statistical modelling to project future requirements for providers based on historic utilization patterns rather than the population's evolving healthcare needs and the effectiveness of health interventions (Birch et al. 2003). In response to shifts in perceptions from surplus to shortage, despite relative stability in provider-topopulation ratios over the last two decades (Chan 2002; Watson et al. 2006), governments and stakeholder groups have called for new approaches to HHR planning that focus on population healthcare needs (Birch et al. 2007; Health Council of Canada 2005). In response, all jurisdictions have endorsed a needs-based planning approach that considers the different levels of need as relative and within the context of a population's demographics, health status and health risks (Birch et al. 1993; Advisory Committee on Health Delivery and Human Resources 2005).

In order to inform efforts to renew PHC, we turned to British Columbians to ask them about their priorities for renewal (Wong et al. 2008). A recurring theme in that discourse was HHR issues. Therefore, the purpose of this study was to conduct a secondary analysis of the qualitative focus group data to better understand British Columbians perspectives on the factors deemed relevant to needs-based planning visà-vis primary healthcare.

\section{Methods}

We conducted 11 focus groups across the province of British Columbia, Canada $(\mathrm{n}=75)$ with English-speaking adults who had visited their PHC provider in the past two years. Focus group sites for each community were selected to be representative of geography, population health status and per capita expenditures on family physicians. Premature mortality rates ranged from 2.01 to 7.33 per 1,000 population, and expenditures on family physicians' services ranged from $\$ 172$ to $\$ 246$ per 1,000 population (Watson et al. 2005). Participants were recruited using random digit dial methods with a sample of telephone numbers pulled by the Canadian Sampler Survey (ASDE 2003). All procedures were approved by University of British Columbia's Behavioural Research Ethics Board.

Focus groups were taped and transcribed, and data were analyzed using Altas.ti software. Next, the co-authors conducted a content analysis using a coding scheme that was developed using the needs-based HHR planning framework collaboratively 
Public Perspectives on Health Human Resources in Primary Healthcare:

Context, Choices and Change

developed and endorsed by governments (Advisory Committee on Health Delivery and Human Resources 2005). We first coded data by broad categories relevant to needs-based planning, such as context, supply, deployment and population health. Then, themes were identified within these categories.

\section{Results}

Participants were predominantly female (65\%), with the majority aged 50 years and older $(62 \%)$, and had more than a high school education (74\%). The average number of chronic illnesses per participant was two, with arthritis (41\%), hypertension (32\%) and depression (29\%) being the most commonly reported. Participants had been with a regular PHC provider on average for 8.5 years.

Three main themes emerged from the data. Patients discussed the importance of geographic context, change management at the practice level and the need for choices and changes in delivery of PHC.

\section{Geographic context affects supply and service delivery}

The intersection between geography and demographic trends, in particular, was related to participants' receipt of services and influenced their perspectives on HHR supply. Participants spoke about the differences among communities in terms of population demographics, geographic location and the services required and received. Many participants in northern or rural areas spoke about the urban-rural differences in PHC access and suggested that geographic issues need to be a factor in planning PHC renewal.

While participants across all focus groups (FG) discussed issues concerning the supply of providers, those living in small communities described an inadequate supply of physicians and other providers:

... the majority of the doctors and nurses are extremely committed people and they take their jobs very seriously and they try their best to give us goodquality care, healthcare. But unfortunately, like a lot of small communities, we have far too many people for far too few caregivers. [FG4]

Participants also discussed economic and political issues, including how healthcare is funded and how resources are allocated ("the problem is that the system looks at the budget one slice of the pie at a time and not the overall cost of the system" [FG7]).

Many participants shared stories of their personal health challenges and made inferences from the personal to the population. That is, knowing the resources they required, they wondered how such needs might affect services at the population level. 
Participants reflected on demographic changes in society, speaking about their own aging, the incidence of chronic illness and health changes in their communities. They expressed concern about how these demographic factors will influence their ability to access PHC services in the future. Some noted geographic differences in population healthcare needs - rural or northern versus urban - with some participants in more rural areas commenting that they had a lower health status than those living in more urban centres: "If you've got heart disease in the north, the chances are that you're going to die sooner." [FG4] Others commented on how health behaviours might affect health needs: "People up north ... they all still smoke." [FG6]

\section{Change management within the context of the clinic}

Another challenge identified by participants relevant for needs-based planning was the context in which people receive PHC services. When participants waited for appointments, waited in the office for more than 15 minutes, or were added to a waiting list to be accepted as a patient, they voiced concerns related to delays in care and unmet healthcare needs. Participants attributed these delays and unmet needs to an insufficient supply of providers, and did not discuss alternative strategies to reduce waits. For example: "... I guess if you push him [the doctor] hard enough he'd take you the next day, but it's pretty hard ... to see me in the same day.... I don't know what the improvement would be, probably get more doctors." [FG3] Another stated: "I went on a waiting list to get in with the doctor that I have." [FG4]

When providers appeared rushed, would see participants for only one health issue, or were abrupt in manner, participants ascribed these behaviours to too many patients for an insufficient supply of providers: "We could easily have three more doctors and then we wouldn't have to wait for two days or three days to come in." [FG2]

\section{Choices and changes: Broadening PHC delivery}

Participants discussed a desire for change in HHR supply and deployment and how PHC services were delivered. Participants wanted to choose the types and, in some cases, the gender of the provider, and when their ability to exercise or act on their choice was constrained, they attributed these experiences to HHR issues. These factors included where participants lived, such as in remote communities; when they perceived that there were not sufficient providers available, such as one physiotherapist or pharmacist for a community; when they were deployed in a way that did not allow easy access, such as a lack of available care on weekends; or when payment for services was required.

Many participants spoke about their experiences with complementary or alternative providers, such as naturopaths or massage therapists. They spoke about using an 
acupuncturist or chiropractor in conjunction with seeing their PHC provider, but also commented on barriers to access such as costs associated with these providers. "I'd like to see more naturopaths ... there's a huge charge to see them.... I can't afford to go see them." [FG8] Some suggested that the government should include these providers in PHC coverage.

The gender of the PHC provider was important for some female participants who identified discomfort in obtaining care provided by a male physician. They suggested a "shortage" of female doctors: "... and wére short of female doctors ... there's lots of male doctors ... but the female ones you can't even get into." [FG2] Others chose to drive to other communities to access a female provider or went on waiting lists to get in to see a female physician. One woman talked about a positive strategy to access a female provider:

one of the good things that they've done ... you don't have to go to a doctor to get a pap [smear] done, you can go to a nurse practitioner to get it done and so what happens is more women will keep continuity. Because what's happening is you get a strange doctor all the time. It takes you awhile to get used to that doctor ... so this way you've got continuity of a woman nurse. [FG5]

Participants discussed the types of PHC services they required or wanted, such as disease prevention, health promotion and chronic illness care: "I think there should be more money spent on preventing these things from happening ... ." [FG7] They connected the importance of services to a holistic approach to $\mathrm{PHC}$ and more efficient use of resources:

All of those like physio, massage therapy, all of that should be covered because if you look at the holistic thing, the big picture, that's going to make an effect on your healthcare.... Like wellness, it's the whole thing, why not cover all those because in the long run having all those things covered would cut down on all the visits to the doctors, right, if you have a better holistic health. [FG8]

They also commented on other services not traditionally funded by the public insurance system in Canada, such as dental care and the link to healthcare needs: "... because some people, when their teeth are bad, it can cause a lot of health problems." [FG1]

Participants noted many instances where they believed that seeing a provider other than a physician would have been more appropriate, such as for immunizations, minor health problems, teaching and screening. They talked about how this approach could free physicians to spend more time with complex patients who required an increased 
level of knowledge and skill: "... expanding what people are allowed to do, what they're trained to do ... so I would like to see ... people allowed to do more with the knowledge they have." [FG9] They also recognized that introducing new or more providers might be threatening for some: "... they need a lot more nurses, and I think the doctors will be threatened by that. ... they didn't want to have just a little bit of competition." [FG2]

Participants wanted a team approach, and having the appropriate provider deliver services:

A nurse in the office can help the doctor.... like I have to get allergy shots. A nurse can do that but there's no nurse in the office, and I'm taking up to 15 minutes of the doctor's time from someone that needs a doctor. [FG3]

I think there's a greater role ... for nurse practitioners ... . [FG7]

Maybe the team approach is the way.... You have a clinic and ... there will be three separate doctors and you see this one this time, this one this time or you're a team, but part of that team is a nurse practitioner. [FG9]

The desire for broader access beyond regular office hours was suggested: "We need more doctors that work on weekends. You get sick on the weekends and you have to go to the walk-in clinic." [FG2] Participants also recognized that appropriate use of providers can contribute to greater efficiency:

I think the whole idea that came up about nurse practitioners would be great, it would save a whole amount of time. Now if every doctor set up his practice [with a nurse practitioner] that you could contact, then I think he could run his practice a lot more efficiently. [FG9]

\section{Discussion}

There are many efforts in Canada and abroad to strengthen PHC, to better align HHR with the evolving needs of populations and to enhance accountability and transparency regarding investments to improve the situation. This is one of the first studies that we know of that sought to examine (a) what factors patients of PHC suggest as important for needs-based HHR planning in their discussions regarding the priorities for PHC renewal and (b) why these factors could be priorities in PHC renewal. This study gives us insights into where improvements could be made in order to increase the quality of primary care services delivered. The results suggest that more attention could be focused on overcoming geographic barriers to providing care, 
change management within office-based practices, and provision of support structures that allow PHC professionals to work closer to their full scope of practice. That these factors align with many strategic directions set out by government and planners (Advisory Committee on Health Delivery and Human Resources 2005) signals the readiness for change in how PHC is delivered and HHR planned.

Our participants were aware of the relevance of temporal shifts in the demographic and morbidity profile of the population and the impact of these on HHR planning. However, participants also cautioned that geographical context, particularly for those living in rural or northern communities, needs to be an important consideration for any HHR planning. The unique context of a community means that "one size fits all" HHR planning is not possible or desirable. While HHR planning often occurs at provincial or health authority levels, our participants suggested that planners will need to find ways to integrate the community level into their planning processes. Smallarea analysis may assist to integrate context into HHR planning (Wennberg 1993). Further, our participants' grasp of the relevance of demographics, health status and health risks was consistent with needs-based approaches to resource allocation (Eyles and Birch 1993).

There are supply-side issues, such as recruitment and retention of family physicians and registered nurses in the PHC sector, geographic variation in availability and shifts in demand for healthcare providers. Federal, provincial and territorial governments have already made significant investments to expand university enrolments, the supply of international medical graduates and family practice nurse practitioners to ensure that more healthcare providers enter practice at the same time that more retire (Health Council of Canada 2005). It takes time to train new healthcare professionals, but we are currently beginning to feel the effects of these public investments (Evans and McGrail 2008).

Importantly, we found that patients desire change to improve the way that $\mathrm{PHC}$ is currently delivered. Over half of Canadians (55\% in 2006, 58\% in 2007) believe that the healthcare system needs major repairs or complete rebuilding (Pollara 2007). At the clinic or practice level, our findings suggest that efforts to improve access to $\mathrm{PHC}$ providers through adoption of proven practices such as innovative appointment scheduling (Murray et al. 2003), shifts in practice hours (Health Council of Canada 2008) and offering group medical visits (Reid et al. 2009) are ways in which the PHC system is trying to address the needs of patients.

\section{Conclusions}

Through innovations in health policy, such as changes in health professions regulation and system redesign (e.g., integrated health networks), PHC providers are required to work differently. PHC can no longer be delivered only within professional silos 
but through interprofessional teams, where providers work closer to their full scope of practice. Our results suggest that more emphasis could be placed on wellness and disease prevention through the use of multiple different types of providers. Indeed, almost half (42\%) of Canadians strongly support funding more wellness promotion and disease prevention education and interventions, and 35\% strongly support increasing investments to help patients manage their chronic illness (Pollara 2007).

Participants discussed their desire for interprofessional PHC teams and appropriate and efficient deployment of providers, an approach that is consistent with federal, provincial and territorial investments in these areas. This view is likewise consistent with Canadians continuing to suggest that access to a variety of providers is an important means of ensuring efficient use of PHC resources, financial and human, and is also imperative in addressing issues of access, appropriate care and wait times (Maxwell et al. 2002). The introduction of nurse practitioners in British Columbia occurred around the time our focus groups were being conducted. Participants appeared aware of this provider, whether through their previous experience elsewhere or actual experience in British Columbia. They seemed to be open to accessing PHC services through new providers.

As with all studies, our results should be interpreted with caution. Only Englishspeaking participants from British Columbia who already had access to PHC participated in these focus groups. Given that PHC is delivered at the provincial level, more work is needed to examine whether these views are similar to those of other populations across Canada. In addition, more work is needed to incorporate views of younger patients. However, a strength of these data is that focus groups were conducted across British Columbia. Our findings suggest areas where there is alignment between policy and patient priorities in needs-based HHR planning. Patients can contribute to decisions on how the current supply of providers could be deployed in order to deliver high-quality PHC services. Their views suggest an openness and readiness to new ways of receiving services, and offer policy makers prescriptions for change.

\section{ACKNOWLEDGEMENTS}

The authors would like to acknowledge all focus group participants and those who helped facilitate this study in their communities. At the time of this study, Ms. Regan was supported by a Canadian Institutes of Health Research - TUTOR-PHC Fellowship and Doctoral Research Award, Michael Smith Foundation for Health Research Senior Graduate Studentship, Western Regional Training Centre and Canadian Nurses Foundation Doctoral Scholarship; Dr. Wong was supported by a career award from the National Institute of Aging (444918-31259); and Dr. Watson was a member of the Centre for Health Services and Policy Research, University of British Columbia. 
Public Perspectives on Health Human Resources in Primary Healthcare:

Context, Choices and Change

Correspondence may be directed to: Sandra Regan, Assistant Professor, University of Western Ontario, Arthur Labatt Family School of Nursing, Health Sciences Addition, Room H34, London ON N6A 5C1; e-mail: sregan4@uwo.ca.

\section{REFERENCES}

Advisory Committee on Health Delivery and Human Resources. 2005. A Framework for Collaborative Pan-Canadian Health Human Resources Planning. Retrieved January 11, 2010. <http://www.hc-sc.gc.ca/hcs-sss/alt_formats/hpb-dgps/pdf/pubs/hhr/2007-frame-cadre/2007frame-cadre-eng.pdf $>$.

ASDE Survey Sampler. 2003. Retrieved January 11, 2010. <http://www.surveysampler.com>. Australian Health Workforce Advisory Committee. 2004. Nursing Workforce Planning in Australia: A Guide to the Process and Methods Used by the Australian Health Workforce Advisory Committee. North Sydney: New South Wales Department of Health. Retrieved January 11, 2010. <http:// www.nhwt.gov.au/documents/Publications/2004/Nursing\%20workforce\%20planning\%20in\%20 Australia.pdf $>$.

Birch, S., J. Eyles, J. Hurley, B. Hutchison and S. Chambers. 1993. "A Needs-Based Approach to Resource Allocation in Health Care." Canadian Public Policy 19: 68-85.

Birch, S., G Kephart, G. Tomblin Murphy, L. O’Brien-Pallas, R. Alder and A. MacKenzie. 2007. Health Human Resources Planning and the Production of Health: Development of an Extended Analytical Framework for Needs-Based Health Resources Planning (Rep. No. 168). Hamilton, ON: McMaster University.

Birch, S., L. O’Brien-Pallas, C. Alksnis, G. Tomblin Murphy and D. Thomson. 2003. “Beyond Demographic Change in Human Resources Planning: An Extended Framework and Application in Nursing." Journal of Health Services and Research Policy 8: 225-29.

Chan, T.B.B. 2002. From Perceived Surplus to Perceived Shortage: What Happened to Canada's Physician Workforce in the 1990s? Ottawa: Canadian Institute for Health Information.

Evans, R.G. and K.M. McGrail. 2008. "Richard III, Barer-Stoddart and the Daughter of Time." Healthcare Policy 3(3): 18-28.

Eyles, J. and S. Birch. 1993. "A Population Needs-Based Approach to Health-Care Resource Allocation and Planning in Ontario: A Link between Policy Goals and Practice?" Canadian Journal of Public Health 84: 112-17.

Health Canada. 2004 (September 16). First Ministers' Meeting on the Future of Health Care 2004: A 10-Year Plan to Strengthen Health Care. Retrieved January 11, 2010. <http://www.hc-sc.gc.ca/ hcs-sss/delivery-prestation/fptcollab/2004-fmm-rpm/index_e.html>.

Health Council of Canada. 2005. Modernizing the Management of Health Human Resources in Canada: Identifying Areas for Accelerated Change. Ottawa: Author.

Health Council of Canada. 2007. Health Care Renewal in Canada: Measuring Up? Annual Report to Canadians, 2006. Ottawa: Author.

Health Council of Canada. 2008. Fixing the Foundation: An Update on Primary Health Care and Home Care Renewal in Canada. Retrieved January 11, 2010. <http://www.healthcouncilcanada.ca/ en $/$ index.php?option $=$ com_content $\&$ task $=$ view $\&$ id $=214 \&$ Itemid $=10>$. 
Law, S., C. Flood and D. Gagnon, on behalf of the Listening for Direction partners. 2008. Listening for Direction III: National Consultation on Health Services and Policy Issues, 2007-2010. Retrieved January 11, 2010. <http://www.chsrf.ca/other_documents/listening/documents/ LfDIII-FINAL_ENG.pdf $>$.

Maxwell, J., K. Jackson, B. Legowski, S. Rosell, D. Yankelovich, P.-G. Forest and L. Lozowchuk. 2002. Report on Citizens' Dialogue on the Future of Health Care in Canada. Ottawa: Commission on the Future of Health Care in Canada.

Murray, M., T. Bodenheimer, D. Rittenhouse and K. Grumbach. 2003. "Improving Timely Access to Primary Care: Case Studies of the Advanced Access Model." Journal of the American Medical Association 289: 1042-46.

National Workforce Taskforce and HR Directorate Department of Health. 2002. HR in the NHS Plan. London, UK: Department of Health.

O’Brien-Pallas, L. 2002. "Where To from Here?” Editorial. Canadian Journal of Nursing Research 33: 3-14.

Pollara. 2007. Health Care in Canada: 10th Annual Edition Survey Results, Part 1. Retrieved January 11, 2010. <http://www.hcic-sssc.ca/pdf/2007_hcic_1.pdf>.

Reid, R.J., P.A. Fishman, O. Yu, T.R. Ross, J.T. Tufano, M.P. Soman and E.B. Larson. 2009.

"Patient-Centered Medical Home Demonstration: A Prospective, Quasi-Experimental, Before and After Evaluation." The American Journal of Managed Care 15(9): e71-e87.

Watson, D.E. and H. Krueger. 2005. Primary Health Care Experiences and Preferences: Research Highlights. Vancouver: University of British Columbia Centre for Health Services and Policy Research.

Watson, D.E., H. Krueger, D. Mooney and C. Black. 2005. Planning for Renewal: Mapping Primary Health Care in British Columbia. Vancouver: University of British Columbia Centre for Health Services and Policy Research.

Watson, D.E., S. Slade, L. Buske and J. Tepper. 2006. "Intergenerational Differences in Workloads among Primary Care Physicians: A Ten-Year, Population-Based Study" Health Affairs 25: 1620-28. Wennberg, J.E. 1993. "Future Direction for Small Area Variations." Medical Care 31: YS75-YS80.

Wong, S.T., D.E. Watson, E. Young and S. Regan. 2008. "What's Important about Primary Health Care? Public priorities." Healthcare Policy 3(3): 89-104. 